\title{
Knowledge, attitudes, and practices of Hong Kong population towards human A/H7N9 influenza pandemic preparedness, China, 2014
}

Emily YY Chan*, Calvin KY Cheng, Greta Tam, Zhe Huang and Poyi Lee

\begin{abstract}
Background: Since SARS epidemic in 2003, Hong Kong has experienced several major epidemic risks, but how general community might react to the repeated infectious diseases health risks have not been studied. In 2013, imported human H7N9 influenza infected cases from China were reported. Our study aims to assess the knowledge, attitude and practice (KAP) concerning A/H7N9 among Hong Kong general population regarding pandemic preparedness in early 2014.

Methods: A cross-sectional, population-based telephone survey study was conducted among the Cantonese-speaking population aged over 15 years in Hong Kong in February 2014. The study survey was composed of 78 KAP questions. Factors associated with individual and household pandemic preparedness were analyzed.

Results: Final study sample was 1,020 with a response rate of $45.9 \%$. Among the respondents, most of them believed personal hygiene and avoidance of avian contacts were effective in preventing H7N9 infections. The majority of respondents had satisfactory hand hygiene practices and avoided touching avian species but did not employ other preventive measures. Female, 25 years old or older, white collar workers, people with chronic diseases and people living in the city center tended to report better hygiene practices. The average State-Trait Anxiety Inventory score was 1.85 , similar to that of the period during the first wave and at the start of the second wave of the H7N9 epidemic. Self-reported face masks wearing when having influenza-like illness in general population dropped from $92.4 \%$ during H5N1 period in 2007 to $39.0 \%$ in this study.

Conclusion: Hong Kong citizens show a low level of anxiety, misconceptions regarding the novel strains as well as gaps between perceived usefulness and practice of preventive measures towards influenza outbreaks. Educational campaigns and framing the issue to increase public and media awareness are crucial in preventing the current public fatigue towards outbreaks.
\end{abstract}

Keywords: Knowledge, Attitude, Practice, Influenza A/H7N9, Pandemic preparedness, Chinese community, Hong Kong

\section{Background}

The experience of SARS coronavirus epidemic in 2003 has radically changed the concept and catalyzed actions globally and locally for combating infectious diseases outbreaks at the community level $[1,2]$. Different health agencies globally are now striving to increase community

\footnotetext{
* Correspondence: emily.chan@cuhk.edu.hk

Collaborating Centre for Oxford University and CUHK for Disaster and Medical Humanitarian Response, JC School of Public Health and Primary Care, Faculty of Medicine, The Chinese University of Hong Kong, Hong Kong, Hong Kong SAR
}

\section{Biomed Central

resilience in combating this emerging infectious disease challenge. In particular, in the Hong Kong Special Administration Region of China, where a number of infectious diseases epidemic originated, resources were invested for enhancing infrastructure, policies and health education for pandemic preparedness and infection control. Whilst population resilience level in Hong Kong in handling infectious disease challenges are thought to be higher than other global cities, the mild clinical outcome of A/H1N1 influenza pandemic in 2009 and the limited transmissibility of the $\mathrm{A} / \mathrm{H} 5 \mathrm{~N} 1$ avian influenza outbreaks 
in humans in 2007 may have modified citizens' attitude and perceived risk towards similar outbreak incidences [3-5], and may have led them to underestimate the emerging A/H7N9 outbreak at the community level. A study conducted between 2006 and 2010 suggested that prolonged warning of a future pandemic was likely to cause pandemic fatigue in the public $[6,7]$. For example, studies showed a decrease in self-reported mask use in case of influenza-like illness symptoms since the SARS in 2003 and post-SARS period [8]. There is currently limited literature to examine how prolonged warning may affect community perception and response to these large scale infectious disease risks.

In March 2013, a human infected H7N9 influenza A virus (A/H7N9) case was first identified in Eastern China and caught global attention $[9,10]$. Serious response level of the Preparedness Plan for Influenza Pandemic was activated in Hong Kong in Dec 2013 [11]. As of August 2014, a total of 450 confirmed cases were reported in various provinces in China [12]. A recent study in Hong Kong during the first wave of H7N9 epidemic in April 2013 showed low population anxiety levels [13]. Although current evidence of sustained human-to-human transmission for $\mathrm{A} / \mathrm{H} 7 \mathrm{~N} 9$ is rare, a small cluster of infected cases within the family showed hospitalization might be required [14-16]. Confirmed case fatality rate was around $20 \%$, although the estimated symptomatic case fatality risk was lower [17]. At that time, there were a substantial number of confirmed cases of human infected cases of H7N9 avian influenza during the second wave of the epidemic (Fig. 1). Meanwhile, the infection rate of seasonal influenza was high in Hong Kong, as reflected by the Government Center for Health protection sentinel surveillance system [4].

Some personal behaviors had been suggested to be effective to control pandemics such as SARS and H5N1 in Hong Kong. Previous studies suggested that close contact with live poultry, visiting public places and the places having confirmed cases were risk factors, while frequent mask use, hand washing, disinfection, and avoidance of eating poultry were protective factors $[13,18,19]$. In this study, we conducted a representative, population-based telephone survey in Hong Kong 1) to investigate the current situation regarding the self-reported knowledge, attitude and practice of pandemic responses at individual level on the second wave human infected A/H7N9 avian influenza outbreak; and 2) to investigate factors associated with the self-reported personal hygiene practices.

\section{Methods}

Study design and study population

A cross-sectional, population-based telephone survey was conducted from 15-28 February 2014 in Hong Kong.

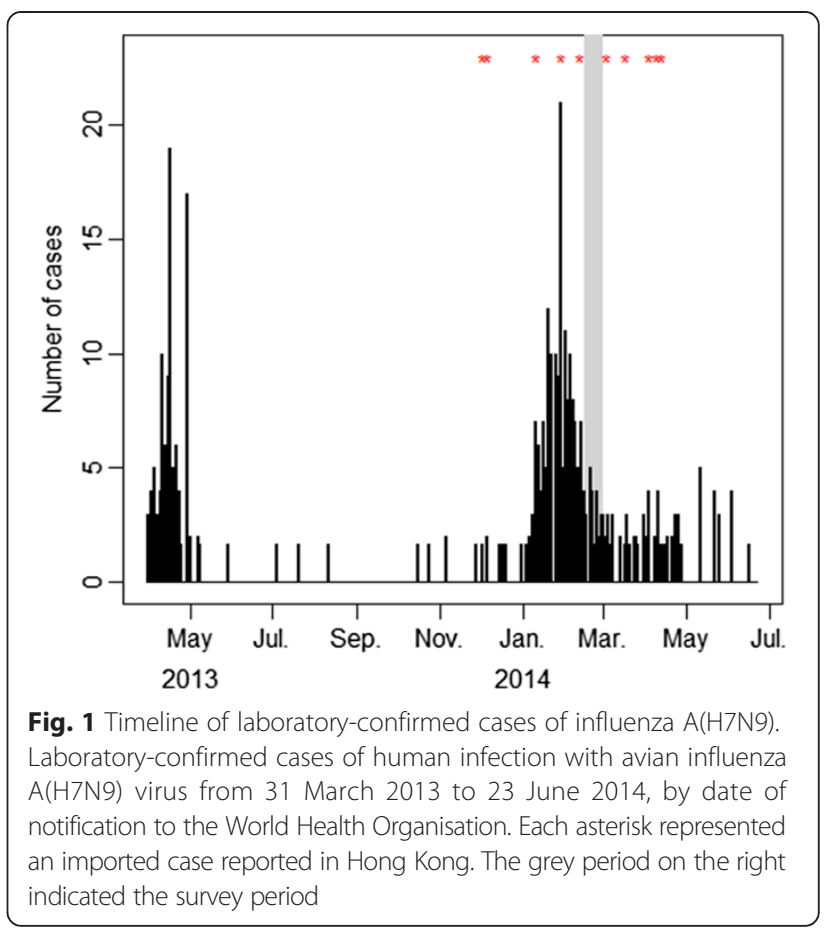

The study population was the population aged 15 years or above residing in Hong Kong, including residents holding valid work or study visas. Exclusion criteria included i) non-Cantonese-speaking respondents; ii) overseas visitors holding tourist visas to Hong Kong; iii) 2-way permit holders from mainland China; and iv) those who were unable to be interviewed due to medical reasons.

\section{Instrument}

A structured Chinese questionnaire was constructed and used for data collection. The questionnaire consisted of 78 closed ended questions that aimed to collect the following information from the respondents:

1. Socio-demographic and background information, including age, gender, district of residence, occupation and employment status, educational attainment, type and size of housing, and household income (total 21 questions).

2. Knowledge of H7N9 influenza A virus, including the differences between H7N9 and other respiratory diseases, transmission routes and "whether seasonal influenza vaccination could protect people from H7N9 infection" (total 9 questions).

3. Attitudes and risk perception towards H7N9 influenza A infections, including attitude towards preventive measures (total 9 questions), perception of H7N9 impact, perceived severity and infectivity, channel preference for information reporting and 
seeking, and their current anxiety level concerning the outbreak (total 30 questions). The 6 questions short form of the State-Trait Anxiety Inventory (STAI) was used for measuring anxiety [20]. A five point Likert-type scale were used to ascertain level of agreement or disagreement for the questions (from 1 to 5, 1 = strongly disagree, $2=$ disagree, 3 = uncertain, $4=$ agree, $5=$ strongly agree).

4. Practices of preventive measures against H7N9 influenza A infections, including personal hygiene practices, avoidance of contact with avian species, household preparedness and vaccination practice (total 18 questions). A four point Likert-type scale were used to ascertain level of the practices (from 1 to 4,1 = always, 2 = often, $3=$ sometimes, $4=$ never).

5. Active personal hygiene practice was defined by practicing 6 or more of the following 9 personal hygiene measures, including wash more hands, wash hands with soap, do not share utensils, wear mask when sick, bring own utensils during meals, avoid going to public places and avoid using public transport, avoid contacting with live poultry, avoid eating poultry and avoid going to places that had H7N9 confirmed cases. Active personal hygiene attitude was defined by regarding 6 or more of the above 9 personal hygiene measures above as useful for prevention H7N9.

Each interview took approximate $15-25 \mathrm{~min}$ to complete. The survey questionnaire was pilot tested in January 2014 $(n=50)$ to ensure practicability, validity, and interpretability of answers. The questionnaire was slightly refined for wording and format before distribution to the study sample based on the results of the pilot study. Results about vaccination practice and channels for disease surveillance have been reported elsewhere and not included in the analysis.

\section{Data collection}

Randomly generated telephone numbers from a list of all land-based telephone numbers in Hong Kong was used as the sample frame [3, 8]. The telephone interviews were conducted by trained interviewers. The telephone calls were made in the evening on weekdays $(6 \mathrm{pm}-10 \mathrm{pm})$ and during daytime and evening on weekends $(10 \mathrm{am}-10 \mathrm{pm})$ to prevent over representation of the unemployed population. The subjects undergoing the interview were chosen based on the "last birthday method" [21, 22], in which the household member who was present in the household during the survey and whose last birthday was closest to the interview date was invited to participate. The subjects were invited on the basis of the proportion of age, gender and living district from the 2011 Hong Kong Population Census data. The sampling would continue until the quotas for each stratum were met. If the selected participant was busy or not there, up to 4 follow-up calls would be made. The numbers were called for a maximum of 5 times before being classified as unanswered.

\section{Statistical analysis}

Differences in proportions between demographic characteristics in this survey and the Hong Kong Population Census data in 2011 were examined. Descriptive statistics for knowledge, attitude and practice of H7N9 influenza A prevention in the study population were calculated. Differences in proportions between groups were tested using Pearson's Chi-square test or Fisher's exact test. Likert-type scale results were collapsed to binary outcomes for analysis. Cut off point for questions with 5 point scales were defined as $>3$ and for questions with 4 point scale as $>2$. Univariate analysis was first conducted to identify apparent associations between individual pandemic preparedness practices with sociodemographic factors, perceived health risk, knowledge and attitudes towards A/H7N9 influenza virus. Backward multivariable logistic regression analyses were then conducted to identify factors associated with actual pandemic preparedness. All variables were retained in the final model if they had $\mathrm{P}$-value $<0.05$. All statistical analyses were conducted using $\mathrm{R}$ (version 3.0.2, $\mathrm{R}$ Development Core Team 2011). Statistical significance was set at $\alpha=0.05$.

\section{Research ethics}

This study was approved by the Survey and Behavioural Research Ethics Committee of The Chinese University of Hong Kong. Oral consent was obtained from each of the participant at the beginning of the study. All collected data were anonymous.

\section{Results}

The final number of respondents who completed the survey was 1020, and the response rate was $45.9 \%$ $(1,020 / 2,221)$. Figure 2 detailed the data collection algorithm and response rate. Table 1 shows the sociodemographic characteristics of the study population compared with the general population in Hong Kong in 2011 [23].

\section{Knowledge of A/H7N9 avian influenza}

Of the respondents, only $25.3 \%$ thought that they had sufficient knowledge to manage the risks that H7N9 avian influenza brings to their health and security. Majority of the respondents $(62.5 \%)$ mistook H7N9 influenza A virus as the common seasonal influenza of the current year and many respondents did not demonstrate 


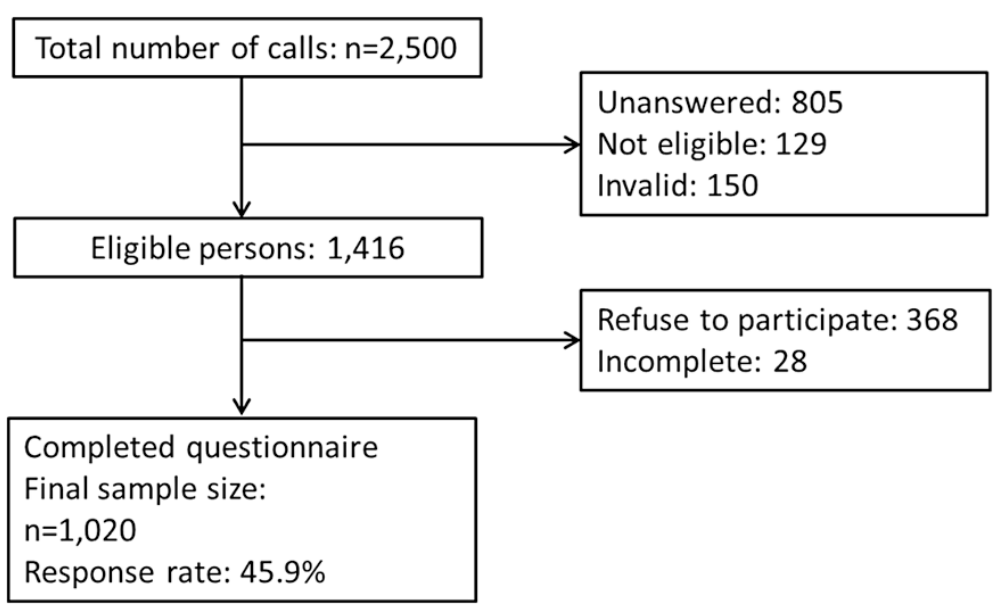

Fig. 2 Study flow of the telephone survey

accurate knowledge of known transmission routes of H7N9. Only $29.0 \%$ of respondents correctly stated H7N9 can be transmitted via animals but not by insects and human feces. More than one fourth (27.5 \%) thought insects can be vector for transmission and more than half (53.9 \%) thought human feces was a possible transmission route. Meanwhile more than half thought those seasonal influenza transmission routes (human saliva $50.5 \%$, air $64.2 \%$, direct hand contact $59.9 \%$, indirect hand contact $55.0 \%$ ) can also transmit H7N9 avian influenza (Table 2).

\section{Attitudinal determinants towards the impact of $\mathrm{A} / \mathrm{H} 7 \mathrm{~N} 9$} Around half (51.8\%) of the respondents regarded Hong Kong as susceptible to infectious diseases outbreaks. The majority $(86.0 \%)$ believed that H7N9 would not acquire the ability of human-to-human transmission within the current year. Most $(72.0 \%)$ of them thought the chances of getting infected by H7N9 within the current year were low or very low. Only a small portion believed the H7N9 outbreak will cause high or very high impact for their health (28.9\%) and economic status (17.0\%). Only $37.8 \%$ believed H7N9 will have high or very high impact affecting society. Respondents believed that H7N9 spread was controllable in general. $26.6 \%$ of respondents did not believe the spread of H7N9 could be prevented at government policy level, and around half (22.6\%) believed that the spread could not be prevented at household and individual level.

The average anxiety level among the respondents towards the current infectious disease outbreak was 1.85 (IQR: $1.33,2.33$ ) on a scale of 1 ("not anxious at all") to 4 ("very anxious"), which was similar to the first wave of H7N9 in April 2013 and during the first imported case in Hong Kong in December 2013 [13].

\section{Attitude and practice towards A/H7N9 personal hygiene} prevention

Overall, most of the respondents thought that active personal hygiene measures reduced the risk of influenza transmission: Washing hands (87.2 \%), using soap for washing hands (88.5\%), not sharing utensils (83.9\%), wearing mask when having respiratory infections (94.4\%), bringing their own utensils during meals (62.0\%), and to a lesser extent, avoiding public places and using public transport (58.4\%). They also had active attitude towards avoiding contact with live poultry (93.1\%), avoiding travel to previous human H7N9 infected areas $(80.9 \%)$ and to a lesser extent, avoiding eating avian species (56.0 \%) (Table 3 ).

While for the actual hygiene practice, most respondents did not practice well the above control measures as shown in Table 3 . Not all measures in practice were dependent with the perceived usefulness, such as washing hands, wearing mask when sick and not sharing utensils during meals. Only hand hygiene $(97.1 \%$ and $72.6 \%)$ and avoiding contact with live poultry (75.2\%) were widely practiced. More than half $(61.0 \%)$ did not wear or just occasionally wore masks when they had respiratory infections. More than half shared utensils (54.1\%), and very few (1.6\%) brought their own utensils during meals when outside home. Over $90 \%$ would not avoid going to public places or using public transport. Around half (55.8\%) would still visit places that had confirmed H7N9 cases.

\section{Factors affecting personal hygiene attitude}

Univariate analysis of different socio-demographic factors, attitudinal determinants towards H7N9 and anxiety level that were associated with active personal hygiene attitude (defined as perceiving 6 or more out of 9 measures above useful) was included in the multivariable 
Table 1 Socio-demographic characteristics of the respondents and the general population in Hong Kong in 2011

\begin{tabular}{llll}
\hline $\begin{array}{l}\text { Sample } \\
\text { population }\end{array}$ & $\begin{array}{l}\text { Hong Kong } \\
\text { population } \\
2011\end{array}$ & $\begin{array}{l}\text { Sample vs. census } \\
\text { 2-value }\end{array}$ \\
\cline { 2 - 3 } & & $\%$ \\
\hline
\end{tabular}

Demographics

Age $(n=1,020)$

\begin{tabular}{|c|c|c|c|}
\hline $15-24$ & 143 & 14.0 & 14 \\
\hline $5-44$ & 348 & 34.1 & \\
\hline $45-64$ & 363 & 35.6 & \\
\hline 65 & 166 & 16.3 & \\
\hline \multicolumn{4}{|l|}{ Gender $(n=1,020)$} \\
\hline lale & 461 & 45.2 & \\
\hline Female & 559 & 54.8 & \\
\hline \multicolumn{4}{|l|}{ Education $(n=1,019)$} \\
\hline Primary education or below & 138 & 13.5 & \\
\hline Secondary education & 517 & 50.7 & \\
\hline $\begin{array}{l}\text { Post-secondary } \\
\text { education(including } \\
\text { diploma and certificate) }\end{array}$ & 364 & 35.7 & \\
\hline \multicolumn{4}{|l|}{ Occupation $(n=1,006)$} \\
\hline White collar & 411 & 40.9 & N \\
\hline Blue collar & 96 & 9.5 & \\
\hline $\begin{array}{l}\text { Housewife, retired or } \\
\text { unemployed }\end{array}$ & 393 & 39.1 & \\
\hline udents & 106 & 10.5 & \\
\hline
\end{tabular}

Area of residence $(n=1,020)$

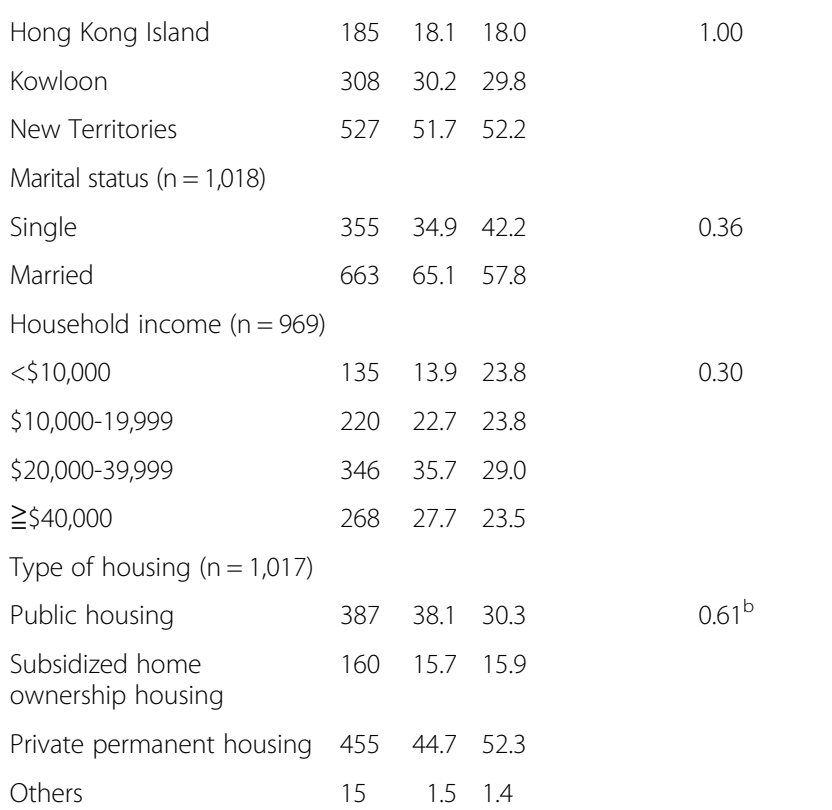

${ }^{\mathrm{a}} \mathrm{Chi}$-square test was used to measure the overall difference in proportions between this survey and the 2011 Hong Kong Population Census data. $P$-value $<0.05$ indicates significant difference

${ }^{\mathrm{b}}$ Fisher-exact test $\mathrm{p}$-value was used
Table 2 Knowledge assessment questions regarding A/H7N9 avian influenza virus

\begin{tabular}{|c|c|c|c|}
\hline Characteristics & Yes (\%) & No $(\%)$ & $\begin{array}{l}\text { Do not } \\
\text { know (\%) }\end{array}$ \\
\hline $\begin{array}{l}\text { Do you think H7N9 is the seasonal flu } \\
\text { of this year? }(n=1,016)\end{array}$ & $637(62.5)$ & $312(30.6)$ & $67(7.0)$ \\
\hline \multicolumn{4}{|c|}{ Do you think H7N9 avian influenza can be spread by? $(n=1,009)$} \\
\hline Droplets by people & $515(50.5)$ & 489(47.9) & $15(1.5)$ \\
\hline Air borne & $655(64.2)$ & $360(35.3)$ & $5(0.5)$ \\
\hline Direct hand contact & $611(59.9)$ & $400(39.2)$ & $8(0.8)$ \\
\hline Indirect hand contact (e.g. via door handle) & $561(55.0)$ & 455(44.6) & $3(0.3)$ \\
\hline Human faeces & $550(53.9)$ & $445(43.6)$ & $25(2.5)$ \\
\hline Animals & $906(88.8)$ & 104(10.2) & 10(1.0) \\
\hline Insects & $281(27.5)$ & $711(69.7)$ & $27(2.6)$ \\
\hline $\begin{array}{l}\text { Do you think seasonal flu vaccination } \\
\text { can protect you from H7N9 virus } \\
\text { infections? }(n=1,019)\end{array}$ & $370(36.3)$ & $614(60.2)$ & $35(3.4)$ \\
\hline
\end{tabular}

analysis. Backward multiple logistic regression revealed female gender $(\mathrm{OR}=1.51,95 \% \mathrm{CI}: 1.08-2.10, \mathrm{P}<0.05)$, working in office environment (compared to "white collar", OR for "blue collar" $=0.55,95 \%$ CI: 0.33-0.92, $\mathrm{P}<0.05)$, and those with high anxiety level towards infectious disease outbreak (compared to "Very low $($ STAI < 1.5)", OR for "Medium(STAI 2.00-2.49)" =1.64, $95 \%$ CI: 1.04-2.58, $\mathrm{P}<0.05)$ had active personal hygiene attitude (Table 4).

\section{Factors affecting personal hygiene practice}

Univariate analysis of different socio-demographic, attitude factors and active attitude towards preventive measures against H7N9 that were associated with active personal hygiene practice (defined as practicing 6 or more out of 9 measures above) was included in the multivariable analysis. Backward multiple logistic regression revealed female gender $(\mathrm{OR}=2.17,95 \% \mathrm{CI}$ : 1.48-3.18, $\mathrm{P}<0.001$ ), older age (compared to age 15-24, OR for age $25-49=4.81,95 \% \mathrm{CI}: 1.37-16.89$; OR for age $50-64=4.46,95 \%$ CI: $1.25-15.95$; OR for age 65 or above $=6.19,95 \%$ CI: $1.60-23.99 . \mathrm{P}<0.05$ for all three), working in office environment (compared to "white collar", OR for "blue collar" $=0.27,95 \%$ CI: 0.11-0.68, P $<0.01$ ), having chronic diseases $(\mathrm{OR}=1.84,95 \% \mathrm{CI}: 1.20-2.82$, $\mathrm{P}<0.01$ ) and living in city center districts (compared to suburb district, OR for densely populated district $=1.59$, $95 \%$ CI: 1.06-2.37, $\mathrm{P}<0.05$; OR for wealthy district $=2.58$, 95 \% CI: 1.65-4.05, $\mathrm{P}<0.001$ ) had better personal hygiene practices.

In terms of attitudinal factors, better personal hygiene practices were associated with those who had active attitude towards personal hygiene practices $(\mathrm{OR}=2.83,95 \% \mathrm{CI}: 1.60-5.01, \mathrm{P}<0.001)$, those with higher anxiety level towards infectious disease outbreak 
Table 3 Perceived usefulness and practice of preventive measures against human A/H7N9 influenza infections

\begin{tabular}{|c|c|c|c|c|c|}
\hline \multirow[t]{2}{*}{ Control measures that can protect from A/H7N9 infections } & \multicolumn{2}{|c|}{$\begin{array}{l}\text { Thought it was useful for } \\
\text { prevention }\end{array}$} & \multicolumn{2}{|c|}{$\begin{array}{l}\text { Always or usually practicing } \\
\text { currently }\end{array}$} & \multirow{2}{*}{$\begin{array}{l}\text { Attitude vs. Practice } \\
\text { p-value }\end{array}$} \\
\hline & $n$ & $\%$ & $\mathrm{n}$ & $\%$ & \\
\hline \multicolumn{6}{|l|}{ Personal hygiene practices } \\
\hline Wash hands more & 888 & 87.2 & 990 & 97.1 & $0.260^{*}$ \\
\hline Use soap to wash hands & 900 & 88.5 & 740 & 72.6 & 0.003 \\
\hline Do not share utensils & 852 & 83.9 & 466 & 45.9 & $<0.001$ \\
\hline Wear mask when sick & 961 & 94.4 & 386 & 39.0 & 0.576 \\
\hline Bring own utensils during meals & 626 & 62.0 & 16 & 1.6 & $0.314^{*}$ \\
\hline Avoid going to public places and use public transport & 592 & 58.4 & 71 & 7.0 & $<0.001$ \\
\hline \multicolumn{6}{|l|}{ Avoid source of $\mathrm{A} / \mathrm{H} 7 \mathrm{~N} 9$ virus } \\
\hline Avoid contacting with live poultry & 949 & 93.1 & 767 & 75.2 & $<0.001$ \\
\hline Avoid eating poultry & 568 & 56.0 & 183 & 17.9 & $<0.001$ \\
\hline Avoid going the places having H7N9 confirmed cases & 820 & 80.9 & 569 & 55.8 & $<0.001$ \\
\hline Had taken at least 6 out of all 9 measures above & 825 & 80.9 & 192 & 18.8 & $<0.001$ \\
\hline
\end{tabular}

*Fisher's exact test

Differences between the two groups were tested by Chi-square or Fisher's exact test. Statistical significant level was set to $p<0.05$

(compared to "Very low (STAI $<1.5)$ ", OR for "High $(\mathrm{STAI}>2.49) "=1.73,95 \% \mathrm{CI}: 1.03-2.92, \mathrm{P}<0.05)$, those who believed H7N9 will obtain human to human transmission in the current year $(\mathrm{OR}=1.85,95 \% \mathrm{CI}: 1.17$ 2.93, $\mathrm{P}<0.01)$, those who thought H7N9 will have higher impact to the Hong Kong society $(\mathrm{OR}=1.67$, $95 \%$ CI: 1.16-2.41, $\mathrm{P}<0.01)$, and those who thought they had sufficient knowledge to manage H7N9 risk $(\mathrm{OR}=1.68,95 \% \mathrm{CI}: 1.17-2.43, \mathrm{P}<0.01)($ Table 5$)$.

\section{Discussion}

We assessed the knowledge, attitude and actual practice of the Hong Kong population for pandemic preparedness during the second wave of human infected H7N9 epidemic in mainland China and when the seasonal influenza activity was high in the community. The result showed respondents still harbored misconceptions of H7N9 influenza, were generally not anxious about the H7N9 outbreak, and were not sufficiently practicing protective measures against infections.

\section{Demographic patterns and knowledge gaps}

Our study found several demographic determinants coincided with other studies in previous literature of respiratory epidemics and pandemics [24]. Female, 25 years old or older, having chronic disease, living in city center district and white collar workers were associated with better preventive behaviors.

Similar to other previous influenza studies [25, 26], respondents did not have detailed understanding of H7N9 avian influenza. A lot of them mixed up A/H7N9 with other types of influenza or other respiratory virus. Mixing up the characteristics may lead to inappropriate health behaviors, making the protection suboptimal or even risky. Although some precautionary measures are similar for preventing H7N9 influenza and other respiratory infections, specific precautions against avian types of influenza, in particular those avoiding contacts with live poultries and their feces should be emphasized to increase individual awareness for better informed protective measures.

\section{Population anxiety and risk perception}

Our study was conducted during the second wave of H7N9 epidemic, at the time, Hong Kong had 5 imported cases with high case fatality ratio, during the winter peak of seasonal influenza. However we found the population still did not take H7N9 seriously. This was reflected in their attitudinal determinants towards the impact of A/H7N9 and their low anxiety level (STAI of 1.85). The population anxiety level was similar to a recent study in Hong Kong during the first wave of H7N9 epidemic in April 2013, and did not increase comparing to the beginning of the second wave when the first case imported in Hong Kong in December 2013 [13]. The anxiety score was also similar to that during the first wave of H1N1 in 2009. In contrast, the anxiety score was much higher (STAI 2.50) during SARS [5]. $74.8 \%$ of Hong Kong population would avoid going to crowded places, and $74.7 \%$ and $71.8 \%$ would avoid going to mainland China and hospitals respectively during SARS period in 2003 [27]. In current study, only $7 \%$ would avoid going to public places and using public transport, and $55.8 \%$ avoid going to places having H7N9 confirmed cases. The findings may indicate public fatigue in response to prolonged warning of influenza pandemic, with 
Table 4 Multiple logistic regression analysis of factors that associate with personal hygiene attitude

\begin{tabular}{|c|c|c|c|c|}
\hline \multirow[t]{2}{*}{ Characteristics } & \multicolumn{2}{|c|}{ aPersonal hygiene attitude } & \multirow[t]{2}{*}{${ }^{b} \mathrm{COR}(95 \% \mathrm{Cl})$} & \multirow[t]{2}{*}{${ }^{\mathrm{c}} \mathrm{AOR}(95 \% \mathrm{Cl})$} \\
\hline & Inactive N (\%) & Active $\mathrm{N}(\%)$ & & \\
\hline \multicolumn{5}{|l|}{ Gender } \\
\hline Male & 105(22.8) & $356(77.2)$ & 1 & 1 \\
\hline Female & $90(16.1)$ & 469(83.9) & $1.54(1.12,2.10)$ & $1.51(1.08,2.10)$ \\
\hline \multicolumn{5}{|l|}{ Age } \\
\hline $15-24$ & $20(14.0)$ & 123(86.0) & 1 & \\
\hline $25-49$ & $62(17.8)$ & $286(82.2)$ & $0.75(0.43,1.30)$ & \\
\hline $50-64$ & $80(22.0)$ & 283(78.0) & $0.58(0.34,0.98)$ & \\
\hline$\geqq 65$ & 33(19.9) & 133(80.1) & $0.66(0.36,1.20)$ & \\
\hline \multicolumn{5}{|l|}{ Occupation } \\
\hline White collar & $74(18.0)$ & $337(82.0)$ & 1 & 1 \\
\hline Blue collar & $28(29.2)$ & $68(70.8)$ & $0.53(0.32,0.89)$ & $0.55(0.33,0.92)$ \\
\hline Housewife, retired or Unemployed & 73(18.6) & $320(81.4)$ & $0.96(0.67,1.38)$ & $0.88(0.61,1.27)$ \\
\hline Student & 16(15.1) & $90(84.9)$ & $1.24(0.69,2.22)$ & $1.22(0.67,2.20)$ \\
\hline \multicolumn{5}{|l|}{ Anxiety score } \\
\hline Very low $(\mathrm{STAl}<1.5)$ & $61(22.0)$ & 216(78.0) & 1 & 1 \\
\hline Low (STAI 1.50-1.99 & $67(23.5)$ & 218(76.5) & $0.92(0.62,1.36)$ & $0.87(0.58,1.30)$ \\
\hline Medium (STAI 2.00-2.49) & $39(14.4)$ & 232(85.6) & $1.68(1.08,2.62)$ & $1.64(1.04,2.58)$ \\
\hline High (STAI >2.49) & 26(14.4) & 155(85.6) & $1.68(1.02,2.78)$ & $1.63(0.98,2.72)$ \\
\hline \multicolumn{5}{|c|}{ Believed Hong Kong is susceptible to infectious diseases outbreaks } \\
\hline No & $108(22.0)$ & $383(78.0)$ & 1 & \\
\hline Yes & $87(16.5)$ & $440(83.5)$ & $1.43(1.04,1.95)$ & \\
\hline \multicolumn{5}{|c|}{ Believed that the spread cannot be prevented at household and individual level } \\
\hline Not enough & 112(21.9) & $399(78.1)$ & 1 & \\
\hline enough & $83(16.4)$ & 424(73.6) & $1.43(1.05,1.97)$ & \\
\hline
\end{tabular}

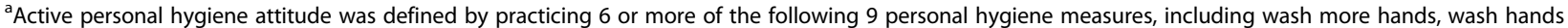
with soap, do not share utensils, wear mask when sick, bring own utensils during meals, avoid going to public places and avoid using public transport, avoid contacting with live poultry, avoid eating poultry and avoid going to places that had H7N9 confirmed cases

${ }^{\mathrm{b}} \mathrm{COR}$, crude odd ratio in the univariate analysis

${ }^{\mathrm{C}} \mathrm{AOR}$, Adjusted odd ratio in the multivariable analysis

people reporting less adoption of infection control behaviours. Though low anxiety level is expected, the misconceptions, inactive attitudes and lack of preventive practices are not optimal for preparedness of future epidemics.

\section{Gaps between perceived usefulness and practice of preventive measures}

There are significant gaps between perceived usefulness and practice of mask wearing and do not share utensils during meals. The population showed high compliance with hand washing. $94 \%$ of the Hong Kong population believed that hand washing was efficacious in preventing human-to-human avian influenza during H5N1 period [19] while $97.8 \%$ perceived washing hands frequently as an effective public health measure during $\mathrm{H} 1 \mathrm{~N} 1$ period [8]. In the current study, this figure was $87.2 \%$. This might be due to public health announcements on mass media, emphasizing the importance of washing hands frequently. In contrast, for mask wearing and utensils sharing, the proportion of actual practices was far lower than perceived usefulness. 92.4 \% of the Hong Kong residents wore face masks when having influenza-like illness during H5N1 period in 2007 [19] and $88.7 \%$ in 2009 during H1N1 period [8]. In the current study, it dropped to $39.0 \%$. Barriers for taking action may be partly due to discomfort when wearing mask, traditional Chinese norm of sharing utensils when dining, and the inconvenience. Nevertheless, our study results showed the main reason hindering individual control behaviors were that people did not consider H7N9 outbreak a serious threat. Their attitude could be reflected by their low perceived severity and infectivity of the virus. Targeted interventions may focus on increasing the awareness of the population towards the outbreak according to current situations. And further analysis will be needed to 
Table 5 Multiple logistic regression analysis of factors that associate with personal hygiene practice

\begin{tabular}{|c|c|c|c|c|}
\hline \multirow[t]{2}{*}{ Characteristics } & \multicolumn{2}{|c|}{${ }^{\text {aPersonal hygiene practice }}$} & \multirow[t]{2}{*}{${ }^{\mathrm{c}} \mathrm{COR}(95 \% \mathrm{Cl})$} & \multirow[t]{2}{*}{${ }^{\mathrm{d}} \mathrm{AOR}(95 \% \mathrm{Cl})$} \\
\hline & Inactive N (\%) & Active N (\%) & & \\
\hline \multicolumn{5}{|l|}{ Gender } \\
\hline Male & $402(87.2)$ & $59(12.8)$ & 1 & 1 \\
\hline Female & $426(76.2)$ & 133(32.8) & $2.13(1.52,2.98)$ & $2.17(1.48,3.18)$ \\
\hline \multicolumn{5}{|l|}{ Age } \\
\hline $15-24$ & 131(91.6) & $12(8.4)$ & 1 & 1 \\
\hline $25-49$ & $281(80.8)$ & $67(19.3)$ & $2.60(1.36,4.98)$ & $4.81(1.37,16.89)$ \\
\hline $50-64$ & 293(80.7) & 70(19.3) & $2.61(1.37,4.98)$ & $4.46(1.25,15.95)$ \\
\hline$\geqq 65$ & 123(74.1) & $43(25.9)$ & $3.82(1.92,7.58)$ & $6.19(1.60,23.99)$ \\
\hline \multicolumn{5}{|l|}{ Marital status } \\
\hline Single & $305(85.9)$ & $50(14.1)$ & 1 & \\
\hline Married & $521(78.6)$ & $142(21.4)$ & $1.66(1.17,2.36)$ & \\
\hline \multicolumn{5}{|l|}{ Occupation } \\
\hline White collar & $332(80.8)$ & $79(19.2)$ & 1 & 1 \\
\hline Blue collar & $90(93.8)$ & $6(6.3)$ & $0.28(0.12,0.66)$ & $0.27(0.11,0.68)$ \\
\hline Housewife, retired or Unemployed & $300(76.3)$ & $93(23.7)$ & $1.30(0.93,1.83)$ & $0.82(0.52,1.29)$ \\
\hline Student & 95(89.6) & $11(10.4)$ & $0.49(0.25,0.95)$ & $1.97(0.53,7.29)$ \\
\hline \multicolumn{5}{|l|}{ Religion } \\
\hline No & $547(83.6)$ & 107(16.4) & 1 & \\
\hline Yes & $280(76.7)$ & $85(23.3)$ & $1.55(1.13,2.14)$ & \\
\hline \multicolumn{5}{|l|}{ Chronic disease } \\
\hline No & $679(83.5)$ & 134(16.5) & 1 & 1 \\
\hline Yes & 148(71.8) & $58(28.2)$ & $1.99(1.39,2.83)$ & $1.84(1.20,2.82)$ \\
\hline \multicolumn{5}{|l|}{ Household type } \\
\hline Public housing & $322(83.2)$ & $65(16.8)$ & 1 & \\
\hline Subsidized home ownership housing & 139(86.9) & $21(13.1$ & $0.75(0.44,1.27)$ & \\
\hline Private permanent housing & $351(77.1)$ & 104(22.9) & $1.47(1.04,2.07)$ & \\
\hline \multicolumn{5}{|l|}{ Vulnerable members } \\
\hline No & $330(84.4)$ & $61(15.6)$ & 1 & \\
\hline Yes & 497(79.1) & 131(20.9) & $1.43(1.02,1.99)$ & \\
\hline \multicolumn{5}{|l|}{ Area of residence } \\
\hline Suburb Districts & $448(85.0)$ & $79(15.0)$ & 1 & 1 \\
\hline Densely Populated Districts & $247(80.2)$ & $61(19.8)$ & $1.40(0.97,2.02)$ & $1.59(1.06,2.37)$ \\
\hline Wealthy Districts & 133(71.9) & $52(28.1)$ & $2.22(1.49,3.31)$ & $2.58(1.65,4.05)$ \\
\hline \multicolumn{5}{|l|}{${ }^{\mathrm{b}}$ Attitude towards hygiene practice } \\
\hline Inactive & 177(90.8) & $18(9.2)$ & 1 & 1 \\
\hline Active & $651(78.9)$ & 174(21.1) & $2.63(1.57,4.39)$ & $2.83(1.60,5.01)$ \\
\hline \multicolumn{5}{|l|}{ Anxiety score } \\
\hline Very low (STAI < 1.50) & $234(84.5)$ & $43(15.5)$ & 1 & 1 \\
\hline Low (STAI 1.50-1.99 & 243(85.3) & $42(14.7)$ & $0.94(0.59,1.49)$ & $0.82(0.49,1.34)$ \\
\hline Medium (STAI 2.00-2.49) & $216(80.0)$ & $55(20.0)$ & $1.39(0.89,2.15)$ & $1.19(0.73,1.94)$ \\
\hline High (STAl > 2.49) & $131(72.4)$ & $50(27.6)$ & $2.08(1.31,3.29)$ & $1.73(1.03,2.92)$ \\
\hline
\end{tabular}


Table 5 Multiple logistic regression analysis of factors that associate with personal hygiene practice (Continued)

\begin{tabular}{|c|c|c|c|c|}
\hline \multicolumn{5}{|c|}{ Believed Hong Kong is susceptible to infectious diseases outbreaks } \\
\hline No & $415(84.5)$ & $76(15.5)$ & 1 & \\
\hline Yes & $412(78.2)$ & 115(21.8) & $1.52(1.11,2.10)$ & \\
\hline \multicolumn{5}{|c|}{ Believed H7N9 will be capable of human-to-human transmission this year } \\
\hline Not likely & $730(83.3)$ & $146(16.7)$ & 1 & 1 \\
\hline Likely & $96(68.1)$ & 45(31.9) & $2.34(1.58,3.48)$ & $1.85(1.17,2.93)$ \\
\hline \multicolumn{5}{|c|}{ Have very high chance to be infected by H7N9 } \\
\hline Not likely & $777(82.0)$ & 171(18.0) & 1 & \\
\hline Likely & $51(71.8)$ & $20(28.2)$ & $1.78(1.04,3.07)$ & \\
\hline \multicolumn{5}{|c|}{ Impact of H7N9 affecting your health } \\
\hline Low impact & $620(83.4)$ & 120(16.6) & 1 & \\
\hline High impact & $220(75.3)$ & $72(24.7)$ & $1.64(1.18,2.28)$ & \\
\hline \multicolumn{5}{|c|}{ Impact of H7N9 to Hong Kong } \\
\hline Low impact & $540(84.9)$ & $96(15.1)$ & 1 & 1 \\
\hline High impact & $287(74.9)$ & $96(25.1)$ & $1.88(1.37,2.58)$ & $1.67(1.16,2.41)$ \\
\hline \multicolumn{5}{|c|}{ Perceived knowledge to combat H7N9 outbreak } \\
\hline Not enough & $602(84.0)$ & 115(16.0) & 1 & 1 \\
\hline Enough & $225(74.8)$ & $76(25.3)$ & $1.77(1.27,2.45)$ & $1.68(1.17,2.43)$ \\
\hline
\end{tabular}

identify other specific barriers and to increase the selfefficacy in overcoming them, thus changing the health behavior for better protection.

\section{Limitations}

Limitations in the study included the methodological limitations of telephone survey. Firstly, households with no possession of a land-based telephone service may be missed. Nonetheless, the penetration rate of residential fixed line service in Hong Kong was $102.6 \%$ in November 2013. The residential fixed line penetration is calculated by dividing the number of residential fixed lines by the number of households in Hong Kong [28]. Almost all households have at least one home based telephone service in Hong Kong. Secondly, our sample population had higher household income and education level than the Hong Kong general population. This may overestimate the overall results as these groups are more knowledgeable and have better practices for pandemic preparedness in general. Thirdly, there may be some reporting bias. Data were self-reported and data from non-respondents could not be obtained.

Our results may not be generalizable to other countries or cities that have not experienced previous severe epidemics such as SARS. This study presents as a unique reference for pandemic preparedness behavioral response during a second wave epidemic in an urban setting. External factors may influence the stability of the responses during the survey period. Nevertheless, we managed to finish the field data collection within a short period (two weeks) to produce a stable response.

\section{Conclusion}

Similar to previous studies, Hong Kong citizens show a low level of anxiety, misconceptions regarding the novel strains as well as gaps between perceived usefulness and practice of preventive measures towards influenza outbreaks. Educational campaigns and framing the issue to increase public and media awareness is crucial in preventing the current public fatigue towards outbreaks.

\section{Availability of data and materials}

Not applicable.

\section{Competing interests}

The authors declare that they have no competing interests.

\section{Authors' contributions}

EYYC and CKYC participated in planning the study, data collection, and interpreting the results. EYYC, PYL, GT and ZH participated in data collection, interpreting the results and final paper writing. EYYC obtained research funding. EYYC and CKYC wrote the first draft of the article. All authors were involved in planning the article, critical review and editing of the first draft, and subsequent revisions to the paper. All authors read and approved the final manuscript. 
Authors' information

Not applicable.

\section{Acknowledgements}

The authors thank all participants of this study and Prof. William B. Goggins for his help in the supporting of statistical analysis. This work has received financial support from the Research Fund for the Control of Infectious Disease, Food and Health Bureau, Government of the Hong Kong SAR (grant no. CU-13-01-01).

Received: 8 January 2015 Accepted: 7 September 2015

Published online: 22 September 2015

\section{References}

1. Demmler GJ, Ligon BL. Severe acute respiratory syndrome (SARS): a review of the history, epidemiology, prevention, and concerns for the future. Semin Pediatr Infect Dis. 2003;14(3):240-4

2. Tai DYH. SARS: how to manage future outbreaks? Ann Acad Med Singapore. 2006;35(5):368-73

3. Lau JTF, Tsui HY, Kim JH, Chan PKS, Griffiths S. Monitoring of perceptions, anticipated behavioral, and psychological responses related to $\mathrm{H} 5 \mathrm{~N} 1$ influenza. Infection. 2010;38(4):275-83.

4. Centre for Health Protection. http://www.chp.gov.hk/. Accessed 21 February 2014

5. Cowling BJ, Ng DMW, Ip DKM, Liao Q, Lam WWT, Wu JT, et al. Community psychological and behavioral responses through the first wave of the 2009 influenza A(H1N1) pandemic in Hong Kong. J Infect Dis. 2010;202(6):867-76.

6. Liao Q, Cowling BJ, Lam WT, Fielding R. Changing Perception of Avian Influenza Risk, Hong Kong, 2006-2010. Emerg Infect Dis. 2011;17(12):2379-80.

7. Li T, Feng J, Qing P, Fan X, Liu W, Li M, et al. Attitudes, practices and information needs regarding novel influenza A (H7N9) among employees of food production and operation in Guangzhou, Southern China: a crosssectional study. BMC Infect Dis. 2014;14(1):4.

8. Lau JTF, Griffiths S, Choi K-C, Lin C. Prevalence of preventive behaviors and associated factors during early phase of the H1N1 influenza epidemic. Am J Infect Control. 2010;38(5):374-80.

9. Parry J. H7N9 avian flu infects humans for the first time. BMJ. 2013:346:f2151.

10. Uyeki TM, Cox NJ. Global concerns regarding novel influenza $A(H 7 N 9)$ virus infections. N Engl J Med. 2013;368(20):1862-4.

11. Government of Hong Kong. Prevention of avian influenza (press releases). http://www.info.gov.hk/gia/general/201312/03/P201312030566.htm. Accessed 13 August 2014

12. WHO | Situation updates - Avian influenza. http://www.who.int/ influenza/human_animal_interface/avian_influenza/archive/en/. Accessed 13 August 2014

13. Wu P, Fang VJ, Liao Q, Ng DMW, Wu JT, Leung GM. Responses to Threat of Influenza A (H7N9) and Support for Live Poultry Markets, Hong Kong, 2013. Emerg Infect Dis. 2014;20(5):3-9.

14. Gao H-N, Lu H-Z, Cao B, Du B, Shang H, Gan J-H, et al. Clinical findings in 111 cases of influenza A (H7N9) virus infection. N Engl J Med. 2013;368(24):2277-85

15. Liu T, Bi Z, Wang X, Li Z, Ding S, Bi Z, et al. One family cluster of avian influenza $A(H 7 N 9)$ virus infection in Shandong, China. BMC Infect Dis. 2014;14(1):98.

16. Qi X, Qian Y-H, Bao C-J, Guo X-L, Cui L-B, Tang F-Y, et al. Probable person to person transmission of novel avian influenza $A$ (H7N9) virus in Eastern China, 2013: epidemiological investigation. BMJ. 2013:347:f4752.

17. Yu H, Cowling BJ, Feng L, Lau EHY, Liao Q, Tsang TK, et al. Human infection with avian influenza A H7N9 virus: an assessment of clinical severity. Lancet. 2013;382(9887):138-45

18. Lau JTF, Tsui H, Lau M, Yang X. SARS transmission, risk factors, and prevention in Hong Kong. Emerg Infect Dis. 2004;10(4):587-92.

19. Lau JTF, Kim JH, Tsui HY, Griffiths S. Anticipated and current preventive behaviors in response to an anticipated human-to-human H5N1 epidemic in the Hong Kong Chinese general population. BMC Infect Dis. 2007;7:18.

20. Marteau TM, Bekker H. The development of a six-item short-form of the state scale of the Spielberger State-Trait Anxiety Inventory (STAI). Br J Clin Psychol. 1992:31(Pt 3):301-6.

21. Chan EYY, Kim JH, Ng Q, Griffiths S, Lau JTF. A descriptive study of nonfatal, unintentional home-based injury in urban settings: evidence from Hong Kong. Asia Pac J Public Health. 2008;20(Suppl):39-48.
22. Chan EYY, Kim JH, Griffiths SM, Lau JTF, Yu I. Does Living Density Matter for Nonfatal Unintentional Home Injury in Asian Urban Settings? Evidence from Hong Kong. J Urban Heal. 2009;86(6):872-86.

23. Census and Statistics Department The Government of the Hong Kong Special Administrative Region. 2011 Population Census. Main Tables. 2012. http://www.census2011.gov.hk/en/main-table.html Accessed 20 Feb 2014

24. Bish A, Michie S. Demographic and attitudinal determinants of protective behaviours during a pandemic: a review. $\mathrm{Br} J$ Health Psychol. 2010;15(Pt 4):797-824.

25. Di Giuseppe G, Abbate R, Albano L, Marinelli P, Angelillo IF. A survey of knowledge, attitudes and practices towards avian influenza in an adult population of Italy. BMC Infect Dis. 2008:8:36

26. Lau JTF, Tsui H, Kim JH, Griffiths S. Perceptions about status and modes of H5N1 transmission and associations with immediate behavioral responses in the Hong Kong general population. Prev Med (Baltim). 2006:43(5):406-10.

27. Lau JTF, Yang X, Pang E, Tsui HY, Wong E, Wing YK. SARS-related Perceptions in Hong Kong. Emerg Infect Dis. 2005;11(3):417-24.

28. Office of the Communications Authority - Key Communications Statistics. http://www.ofca.gov.hk/mobile/en/media_focus/data_statistics/key_stat/ index.html. Accessed 21 Feb 2014

\section{Submit your next manuscript to BioMed Central and take full advantage of:}

- Convenient online submission

- Thorough peer review

- No space constraints or color figure charges

- Immediate publication on acceptance

- Inclusion in PubMed, CAS, Scopus and Google Scholar

- Research which is freely available for redistribution

Submit your manuscript at www.biomedcentral.com/submit
C Biomed Central 